\title{
Genetic characterization of an X-STR decaplex system in the State of Mato Grosso, Brazil: distribution, forensic efficiency and population structure
}

\author{
Joyce A. Martins ${ }^{1}$ • Denise P. Martins ${ }^{1}$ - Camila I. F. Oliveira-Brancati ${ }^{1}$. \\ Juliana Martinez $^{2}$ - Regina M. B. Cicarelli ${ }^{2}$ - Dorotéia R. S. Souza ${ }^{1}$
}

Received: 7 October 2016/Accepted: 17 March 2017 / Published online: 12 April 2017

(C) Springer-Verlag Berlin Heidelberg 2017

\begin{abstract}
Studies with X-STR loci show population genetic substructure, which makes necessary the characterization of such markers in the different geographical and/or ethnic populations. Therefore, this study assessed the distribution and forensic efficiency of an X-STR decaplex system in the population of the State of Mato Grosso, as well as analysed the population structure of this State based on the aforementioned system. All X-STR markers were in Hardy-Weinberg equilibrium and linkage equilibrium, and the DXS6809 was the most informative marker. The power of discrimination value in females and males was 0.99999999995 and 0.9999994 , respectively. Analysis of molecular variance indicated $1.10 \%$ $(p<0.00001)$ of heterogeneity among Europeans, Africans, Brazilians and other Latin Americans, and in relation to such groups, the population of the State of Mato Grosso showed lower genetic variation when compared with the Brazilian group $(-0.10 \%, p=0.67327)$. The genetic distance analysis showed lower values of $F_{\mathrm{ST}}\left(0.0004 \leq F_{\mathrm{ST}} \leq 0.00331\right)$, with non-significant $p$ value $(p>0.00024)$, between the populations of Mato Grosso and Mato Grosso do Sul, Paraná and the Southeast region of Brazil (except for one sample of Rio
\end{abstract}

Electronic supplementary material The online version of this article (doi:10.1007/s00414-017-1578-6) contains supplementary material, which is available to authorized users.

Joyce A. Martins

joyce_apa@hotmail.com

1 Research Centre for Biochemistry and Molecular Biology at the Medical School of São José do Rio Preto-FAMERP, Av. Brigadeiro Faria Lima, 5416, São José do Rio Preto, SP 15090-000, Brazil

2 School of Pharmaceutical Sciences, Laboratory of Paternity Investigation, Univ Estadual Paulista-UNESP, Rodovia Araraquara-Jaú, km 01, Araraquara, SP 14801-902, Brazil de Janeiro). $F_{\mathrm{ST}}$ values with significant $p$ values $(p \leq 0.00024)$ were obtained between the population of Mato Grosso and Iberian, African and some Latin American populations. The X-STR decaplex system proved to be extremely useful in the population of the State of Mato Grosso, and the data obtained does not show the need for a specific forensic database for this State in relation to the Brazilian populations compared in this study, except for population of Rio de Janeiro.

Keywords X-STR · Population structure · Mato Grosso · Brazil

\section{Introduction}

The genotype analysis of X-chromosomal short tandem repeat (X-STR) markers is broadly used in some complex cases of biological relationships [1]. This is due to the inheritance pattern of the X chromosome, by which males can only inherit the mother's genetic material and transmit it only to their daughters. Thus, in some investigations, X-STRs have a higher mean exclusion chance (MEC), as well as a more efficient haplotype typing than autosomal markers [1]. If a mother-son relationship is being questioned, for example, $\mathrm{X}$-STR analysis allows for a nearly twofold greater power of exclusion than that obtained for autosomal STRs (ASSTRs) with moderate heterozygosity [2]. In addition, XSTRs can differentiate pedigrees involving two non-inbred individuals (half-siblings, grandparent-grandchild and avuncular), as well as some situations of incest, which are indistinguishable by the analysis of unlinked autosomal markers [3]. Among other applications, there are tests in which the alleged father is absent or unavailable, which can be more easily solved with X-STRs than AS-STRs if the alleged paternal grandmother is analysed. In her absence, her profile 
will also be better determined for X-STRs when analyzing the siblings of the alleged father [1].

Several X-STR loci have been reported for forensic purposes, and 55 loci are characterized in the ChrX-STR. org 2.0 database [4]. Only three kits were available for the analysis of these markers: Mentype ${ }^{\circledR}$ Argus X-UL (Biotype AG), Mentype ${ }^{\circledR}$ Argus X-8 (Biotype AG) and finally, the Investigator Argus X-12 (Qiagen), considered the latest technology in X-STR testing [5]. However, in Brazil, population genetic data was reported for 42 X-STRs [6, 7], especially markers of the 10-plex system implemented by Gusmão et al. [8] and the 12-plex system developed by RibeiroRodrigues et al. [9, 10]. This data is observed in 20 of the 27 Brazilian States (including Federal District); the Northeast and Midwest were the least studied regions and there is no information for the State of Mato Grosso (Midwest).

Therefore, this study characterized the X-STR 10-plex system [8] in the population of the State of Mato Grosso-Brazil (Supplementary Fig. S1), and assessed the genetic structure of this population both inside and outside Brazil, based on that system. This is a pioneer genetic investigation using the XSTRs in the population of the State of Mato Grosso and plays an important role in understanding its formation history.

\section{Materials and methods}

\section{Sampling}

A total of 274 unrelated subjects (100 females and 174 males), residents of the State of Mato Grosso (Brazil), were analysed. This study was approved by the Research Ethics Committee of the Medical School of São José do Rio Preto-FAMERP (CAAE 39088514.8.0000.5415). All participants were informed of the study and signed an informed consent document.

\section{DNA extraction and marker genotyping}

Genomic DNA was extracted from a piece of Whatman FTA ${ }^{\circledR}$ card $\left(4 \mathrm{~mm}^{2}\right)$ containing peripheral blood. For this purpose, $5 \%$ suspension of Chelex 100 resin (Bio-Rad) was used, as indicated by GE Healthcare [11], with minor modifications: $200 \mu \mathrm{L}$ of Milli-Q water was used and centrifugation lasted 2 min.

Amplification of the 10 X-STR markers was performed in a Swift Maxi thermocycler (ESCO, LOBOV Científica), according to Martins et al. [12]. However, $1.5 \mu \mathrm{L}$ of the solution with the extracted DNA was used. The PCR products were separated by capillary electrophoresis using a 3500 Genetic Analyzer (AB-TFS: Applied Biosystems, Thermo Fisher Scientific), and with GeneScan 600 LIZ Size Standard (AB-TFS) and POP-4 ${ }^{\mathrm{TM}}$ polymer
(AB-TFS). Genotyping was performed with GeneMapper® ID-X Software version 1.2 (AB-TFS) through comparison with the reference sample 9947A (Promega Corporation).

\section{Statistical analysis}

The Arlequin software version 3.5.1.3 [13] was used to determine allele frequencies, exact test for Hardy-Weinberg equilibrium in female samples and exact test for linkage disequilibrium in male samples. Statistical parameters of forensic evaluation, including mean exclusion chance in trios involving daughters $\left(\mathrm{MEC}_{\mathrm{T}}\right)$, mean exclusion chance in father/ daughter duos $\left(\mathrm{MEC}_{\mathrm{D}}\right)$, mean exclusion chance in deficiency cases involving mother, daughter and paternal grandmother $\left(\mathrm{MEC}_{\mathrm{PGM}}\right)$, power of discrimination in females $\left(\mathrm{PD}_{\mathrm{F}}\right)$ and power of discrimination in males $\left(\mathrm{PD}_{\mathrm{M}}\right)$, were calculated using the ChrX-STR.org 2.0 database [4].

Analysis of molecular variance (AMOVA) and an estimate of genetic distance $\left(F_{\mathrm{ST}}\right)$ between pairs of populations were performed with the Arlequin software version 3.5.1.3 [13]. The genetic distances $\left(F_{\mathrm{ST}}\right)$ were visualized in a twodimensional graph obtained from the analysis of multidimensional scaling (MDS) using the STATISTICA TRIAL 13.0 (StatSoft Inc., http://www.statsoft.com.br).

\section{Results and discussion}

The allelic profiles typed for $10 \mathrm{X}$-STRs loci in the population of the State of Mato Grosso are shown in Supplementary Tables S1.1 and S1.2, and the allele frequency distribution and forensic statistical parameters to evaluate the efficiency of this system in that population were determined for the total sample (Table 1).

Considering the studied population and other 23 populations who were analysed using the X-STR decaplex system [8, 12, 14-17], the alleles 13.2 (DXS7132), 34.1 (DXS6809) and 8.2 (DXS9898) were observed only in the State of Mato Grosso (Brazil). Also, according to these studies (including this study), intermediate alleles were absent at the loci DXS8378, DXS6789, DXS7133 and GATA31E08; only the alleles 8.2 and 14.2 were mentioned for GATA172D05 [17] and DXS7423 [16], respectively; and various intermediate alleles were reported for DXS9898, DXS9902, DXS7132 and DXS6809, with the last two loci holding the largest number of such alleles (DXS7132: 13.2, 13.3, 14.3, 15.3, 16.3, 17.3, 18.3; DXS6809: 30.1, 31.1, 31.3, 32.1, 33.1, 34.1, $34.2,35.1,38.1,39.1$ ), which implies greater attention to the allelic designation of these markers.

Only the marker DXS9898 showed significant deviation from Hardy-Weinberg equilibrium (Table $1 ; p=0.02418$ ), but it did not remain significant after Bonferroni correction (significance level of 0.005). The marker DXS6809 showed 
Table 1 Allele frequency distribution and forensic statistical parameters for X-STR decaplex system in the population of the State of Mato Grosso (Brazil) as well as observed (Ho) and expected (He) heterozygosity in females with corresponding $p$ values for Hardy-Weinberg equilibrium test ( $p$ HWE)

\begin{tabular}{|c|c|c|c|c|c|c|c|c|c|c|}
\hline & DXS8378 & DXS9898 & DXS7133 & GATA31E08 & GATA172D05 & DXS7423 & DXS6809 & DXS7132 & DXS9902 & DXS6789 \\
\hline$N$ & 374 & 374 & 371 & 374 & 374 & 374 & 374 & 374 & 374 & 372 \\
\hline 6 & & & & & 0.15775 & & & & & \\
\hline 7 & & 0.00535 & 0.00539 & 0.00802 & 0.02139 & & & & & \\
\hline 8 & & & 0.00809 & 0.01604 & 0.13369 & 0.00535 & & & & \\
\hline 8.2 & & 0.00267 & & & & & & & & \\
\hline 8.3 & & 0.14171 & & & & & & & & \\
\hline 9 & 0.00267 & 0.01070 & 0.41507 & 0.13904 & 0.15508 & & & & 0.02139 & \\
\hline 10 & 0.35027 & 0.02941 & 0.16712 & 0.04011 & 0.24866 & & & & 0.03743 & \\
\hline 11 & 0.38235 & 0.13904 & 0.36119 & 0.16310 & 0.20588 & & & 0.01337 & 0.32353 & \\
\hline 12 & 0.23529 & 0.29411 & 0.03504 & 0.30481 & 0.07487 & 0.00802 & & 0.09091 & 0.41979 & \\
\hline 12.1 & & & & & & & & & 0.01604 & \\
\hline 13 & 0.02674 & 0.27273 & 0.00270 & 0.21390 & 0.00267 & 0.05882 & & 0.29947 & 0.17112 & \\
\hline 13.1 & & & & & & & & & 0.00267 & \\
\hline 13.2 & & & & & & & & 0.00267 & & \\
\hline 13.3 & & 0.01070 & & & & & & & & \\
\hline 14 & 0.00267 & 0.08556 & 0.00270 & 0.10963 & & 0.32086 & & 0.30749 & 0.00802 & 0.00269 \\
\hline 15 & & 0.00802 & 0.00270 & 0.00535 & & 0.44652 & & 0.17914 & & 0.11828 \\
\hline 15.3 & & & & & & & & 0.00535 & & \\
\hline 16 & & & & & & 0.10695 & & 0.06417 & & 0.09677 \\
\hline 16.3 & & & & & & & & 0.02139 & & \\
\hline 17 & & & & & & 0.05348 & & 0.01337 & & \\
\hline 17.3 & & & & & & & & 0.00267 & & \\
\hline 18 & & & & & & & & & & 0.00806 \\
\hline 19 & & & & & & & & & & 0.03226 \\
\hline 20 & & & & & & & & & & 0.32258 \\
\hline 21 & & & & & & & & & & 0.23118 \\
\hline 22 & & & & & & & & & & 0.13441 \\
\hline 23 & & & & & & & & & & 0.04839 \\
\hline 24 & & & & & & & & & & 0.00538 \\
\hline 27 & & & & & & & 0.00267 & & & \\
\hline 28 & & & & & & & 0.02941 & & & \\
\hline 29 & & & & & & & 0.03743 & & & \\
\hline 30 & & & & & & & 0.06417 & & & \\
\hline 31 & & & & & & & 0.12299 & & & \\
\hline 31.1 & & & & & & & 0.00267 & & & \\
\hline 32 & & & & & & & 0.15241 & & & \\
\hline 32.1 & & & & & & & 0.00267 & & & \\
\hline 33 & & & & & & & 0.28342 & & & \\
\hline 34 & & & & & & & 0.16578 & & & \\
\hline 34.1 & & & & & & & 0.00535 & & & \\
\hline 35 & & & & & & & 0.09358 & & & \\
\hline 35.1 & & & & & & & 0.00267 & & & \\
\hline 36 & & & & & & & 0.02406 & & & \\
\hline 37 & & & & & & & 0.01070 & & & \\
\hline Ho & 0.64000 & 0.68000 & 0.77778 & 0.82000 & 0.85000 & 0.68000 & 0.81000 & 0.79000 & 0.67000 & 0.76768 \\
\hline $\mathrm{He}$ & 0.67889 & 0.79729 & 0.68036 & 0.79191 & 0.83648 & 0.68216 & 0.83995 & 0.77236 & 0.67688 & 0.78808 \\
\hline$p$-HWE & 0.51971 & 0.02418 & 0.59864 & 0.78354 & 0.78811 & 0.42638 & 0.34331 & 0.75156 & 0.13044 & 0.80871 \\
\hline
\end{tabular}


Table 1 (continued)

\begin{tabular}{|c|c|c|c|c|c|c|c|c|c|c|}
\hline & DXS8378 & DXS9898 & DXS7133 & GATA31E08 & GATA172D05 & DXS7423 & DXS6809 & DXS7132 & DXS9902 & DXS6789 \\
\hline $\mathrm{PD}_{\mathrm{F}}$ & 0.82828 & 0.92664 & 0.82702 & 0.93309 & 0.94444 & 0.84547 & 0.95555 & 0.91270 & 0.84773 & 0.93236 \\
\hline $\mathrm{PD}_{\mathrm{M}}$ & 0.67503 & 0.79119 & 0.66799 & 0.80143 & 0.82290 & 0.67982 & 0.83794 & 0.77044 & 0.68764 & 0.79759 \\
\hline $\mathrm{MEC}_{\mathrm{T}}$ & 0.60891 & 0.76143 & 0.60523 & 0.77395 & 0.79871 & 0.62780 & 0.81975 & 0.73584 & 0.63293 & 0.77093 \\
\hline $\mathrm{MEC}_{\mathrm{D}}$ & 0.46197 & 0.63429 & 0.45931 & 0.64937 & 0.68038 & 0.48328 & 0.70979 & 0.60358 & 0.48819 & 0.64625 \\
\hline $\mathrm{MEC}_{\mathrm{PGM}}$ & 0.39634 & 0.59584 & 0.40087 & 0.61234 & 0.64569 & 0.43451 & 0.68365 & 0.56152 & 0.43441 & 0.61123 \\
\hline
\end{tabular}

$N$ number of chromosomes, $P D_{F}$ power of discrimination in females, $P D_{M}$ power of discrimination in males, $M E C_{T}$ mean exclusion chance in trios involving daughters, $M E C_{D}$ mean exclusion chance in father/daughter duos, $M E C_{P G M}$ mean exclusion chance in deficiency cases involving mother, daughter and paternal grandmother

the highest forensic efficiency values, whereas DXS7133, DXS8378 and DXS7423 were the least effective markers (Table 1). These results were obtained in 17 (for DXS6809) and 14 (for DXS7133, DXS8378 and DXS7423) of the 23 populations analysed using the same genetic system $[8,12$, 14-17]. The power of discrimination value in females and males was 0.99999999995 and 0.9999994, respectively. For the evaluation of biological relationships, the overall $\mathrm{MEC}_{\mathrm{T}}$, $\mathrm{MEC}_{\mathrm{D}}$ and $\mathrm{MEC}_{\mathrm{PGM}}$ values were 0.999998, 0.9999 and 0.9997, respectively. The results show that the X-STR decaplex system is highly informative for the population of the State of Mato Grosso (Brazil), as described in other Brazilian populations [8, 12, 15].

Analysis of linkage disequilibrium (LD) (Supplementary Table S2) showed allelic association $(p \leq 0.05)$ only at pairs DXS9898/DXS7132 $(p=0.0149)$, DXS6809/DXS9902 $(p=0.0491)$ and DXS9898/DXS6789 $(p=0.0142)$, whose loci are spaced by more than 7.65 Mb (Rutgers Map v.3, http://compgen.rutgers.edu/download_maps.shtml). However, LD did not remain after Bonferroni correction (significance level of 0.0011), and these allelic associations were not consistent with other admixed populations of the Brazilian Midwest, Southeast and South, which were evaluated based on the same X-STR system [8, 12].

For the DXS6809-DXS6789 markers, which are closely linked $(0.35 \mathrm{cM})$, an allelic association was reported in one sample of the German population [18]. However, such association could not be observed in the population of Mato Grosso, other admixed populations in Brazil [8, 12] and populations in Latin America [8], Iberian countries [8, 16, 19], Italy [20], Africa [14, 17, 21] and Japan [22].

The linkage equilibrium found in Europeans [8, 16, 19] and Africans [14, 17] (considering the Bonferroni correction) for the X-STR decaplex system suggests that LD was not inherited from these groups during the formation of the population of Mato Grosso (Brazil). Moreover, the absence of LD for these loci in the studied population shows that mixing of different racial groups did not result in significant allelic association, which increased the power of discrimination to the multiplex system and allows the use of allele frequency database for such markers, including DXS6809 and DXS6789 loci.

Analysis of molecular variance (AMOVA) was carried out with the allelic profiles obtained from the X-STR decaplex system in four European populations (Portugal: northern and central regions [8]; Spain: Galicia and Cantabria [8]), one African population (Uganda: Karimojong [14]), nine Brazilian populations (Mato Grosso-this study; Mato Grosso do Sul [8], São Paulo [8], Rio de Janeiro [8], Paraná [8], São Paulo [12], Rio de Janeiro [12], Vitória [12] and Belo Horizonte [12]) and seven other Latin American populations (Argentina: Buenos Aires [8], Cordoba [8], Rio Negro [8], Entre Rios [8] and Missiones [8]; Colombia: Antioquia [8]; Costa Rica [8]). Asian and Native American populations with available data about allelic profiles for such X-STR system could not be found in the literature. This analysis was performed in five tests (Table 2), and the results showed that most of the genetic variability (above $96.60 \% ; p<0.00001$ ) was due to differences within the populations. However, there was significant variation $(p \leq 0.05)$ among the populations within the studied groups and among some groups, $1.10 \%$ $(p<0.00001)$ of heterogeneity was observed among the groups of European, African, Brazilian and other Latin American countries. The State of Mato Grosso, in relation to the different geographical groups (tests 2 to 5), showed lower genetic variation when compared with the Brazilian group $(-0.10 \%)$, followed by Latin American $(0.19 \%)$, European $(0.52 \%)$ and African $(3.40 \%)$.

Genetic distances, based on the number of different alleles $\left(F_{\mathrm{ST}}\right)$, were estimated for the X-STR decaplex system (Supplementary Table S3), using the same populations described in the AMOVA analysis. Low genetic distance values $\left.0.0004 \leq F_{\mathrm{ST}} \leq 0.00331\right)$ with non-significant $p$ value ( $p>0.00024$ after Bonferroni correction) were obtained for the population of Mato Grosso in relation to the Brazilian populations, except for one sample of Rio de Janeiro to which further studies are needed to evaluate this genetic differentiation. Internationally, the population of Mato Grosso showed increased genetic similarity with the Argentine population $\left(0.00437 \leq F_{\mathrm{ST}} \leq 0.00581\right.$, except Entre Rios), followed by 
Table 2 Analysis of molecular variance (AMOVA) for X-STR decaplex system in different population groups

\begin{tabular}{|c|c|c|c|c|}
\hline Test & Population & Source of variation & Variation $(\%)$ & $p$ \\
\hline \multirow[t]{3}{*}{ Test 1} & European & Among groups & 1.10 & $<0.00001^{*}$ \\
\hline & $\begin{array}{l}\text { African } \\
\text { Latin American }^{\mathrm{a}}\end{array}$ & Among populations within groups & 0.33 & $<0.00001^{*}$ \\
\hline & Brazilian $^{\mathrm{b}}$ & Within populations & 98.57 & $<0.00001 *$ \\
\hline \multirow[t]{3}{*}{ Test 2} & Mato Grosso, Brazil & Among groups & 0.52 & 0.20079 \\
\hline & European & Among populations within groups & 0.17 & $0.00089 *$ \\
\hline & & Within populations & 99.31 & $<0.00001 *$ \\
\hline \multirow[t]{2}{*}{ Test 3} & Mato Grosso, Brazil & Among populations & 3.40 & $<0.00001^{*}$ \\
\hline & African & Within populations & 96.60 & \\
\hline \multirow[t]{3}{*}{ Test 4} & Mato Grosso, Brazil & Among groups & 0.19 & 0.38386 \\
\hline & Latin American ${ }^{\mathrm{a}}$ & Among populations within groups & 0.51 & $<0.00001 *$ \\
\hline & & Within populations & 99.30 & $<0.00001 *$ \\
\hline \multirow[t]{3}{*}{ Test 5} & Mato Grosso, Brazil & Among groups & -0.10 & 0.67327 \\
\hline & Brazilian $^{\mathrm{c}}$ & Among populations within groups & 0.32 & $<0.00001^{*}$ \\
\hline & & Within populations & 99.78 & $<0.00001^{*}$ \\
\hline
\end{tabular}

\footnotetext{
* Significant $p$ values for a level of 0.05

${ }^{a}$ Latin American: Buenos Aires [8], Cordoba [8], Rio Negro [8], Entre Rios [8], Missiones [8], Antioquia [8] and Costa Rica [8]

${ }^{\mathrm{b}}$ Brazilian: Mato Grosso [this study], Mato Grosso do Sul [8], São Paulo [8], Rio de Janeiro [8], Paraná [8], São Paulo [12], Rio de Janeiro [12], Vitória [12] and Belo Horizonte [12]

${ }^{\mathrm{c}}$ Brazilian: include all Brazilian populations reported for Brazilian ${ }^{\mathrm{b}}$ group, except Mato Grosso [this study]
}

Iberians ( $0.00559 \leq F_{\mathrm{ST}} \leq 0.00663$, except Cantabria), as well as greater genetical distance from the African population $\left(F_{\mathrm{ST}}=0.03404\right)$. Significant $p$ values $(p \leq 0.00024$ after Bonferroni correction) were observed when comparing the population of Mato Grosso with the Iberian, African and some Latin American populations (Cordoba, Buenos Aires, Costa Rica and Antioquia). This demonstrates a need for specific allelic databases for different populations. Although the genetic distance to Entre Rios $\left(F_{\mathrm{ST}}=0.01008 ; p=0.00574\right.$ ) was greater than the Argentine estimates, it was not statistically significant. Pairwise analysis of $F_{\mathrm{ST}}$ revealed some significant genetic differences, which were not observed in the AMOVA test.

Multidimensional scaling analysis (MDS) based on the matrix of $F_{\mathrm{ST}}$ is shown in Fig. 1, which shows that the population of Mato Grosso is grouped into the Brazilian populations, especially Mato Grosso do Sul (belonging to the Midwest region of Brazil, where Mato Grosso is located). It is also closer to the Argentine group, followed by the Iberian group, and very distant from the African population, which is consistent with the data obtained from the AMOVA and $F_{\mathrm{ST}}$ analyses.

Considering the X-STR decaplex system in the Brazilian Midwest, the population of Mato Grosso shows similar $F_{\mathrm{ST}}$ results to those of Mato Grosso do Sul [8, 12], especially within a national context, as observed in the MDS graph. In a study with 12 X-STRs in 16 Brazilian States of all five geopolitical regions of the country [19], Mato Grosso do Sul also showed no significant differences with the other States. Goiás, a Midwest State, differed from Rondonia only. When all Brazilian regions were compared among each other, the Midwest did not differ from the other regions and showed more similarities to the Northwest and Southeast of Brazil, followed by the South and finally the North, confirming the data obtained in this study. However, statistically significant differences are found among some Brazilian populations for the X-STR decaplex [8, 12] and 12-plex systems [19], which demonstrate that a national database should not be used for such markers in Brazil.

According to Moura et al. [24], the populations in the Midwest (MW) and Southeast (SE) of Brazil have similar genetic composition for autosomal markers (MW 64\% European (E), 24\% African (A) and 12\% Native American (NA); SE $67 \%$ E, 23\% A and 10\% NA), and it is also closer to the genetic composition of the Northeast (NE 58\% E, 27\% $\mathrm{A}$ and $15 \% \mathrm{NA}$ ). These findings have also been reported by Manta et al. for 46 AIM-Indels [25]. Ancestry estimates based on 24 X-Indel markers in four Brazilian regions confirm similarities between the Southeast and the Northeast (SE 38\% E, $35 \% \mathrm{~A}$ and $27 \% \mathrm{NA}$; NE $37 \%$ E, 36\% A and 27\% NA) [26]. Although the Midwest has not been analysed, it is believed that the ancestry composition for the $\mathrm{X}$ chromosome is similar to these regions, as observed in autosomal studies [24, 25]. These findings are in agreement with the data obtained for the population of Mato Grosso in this study and for other populations of the Brazilian Midwest [8, 12, 19]. 
Fig. 1 MDS plot based on the pairwise $F_{\text {ST }}$ genetic distance matrix, supplementary Table S3, $($ stress $=0.10)$

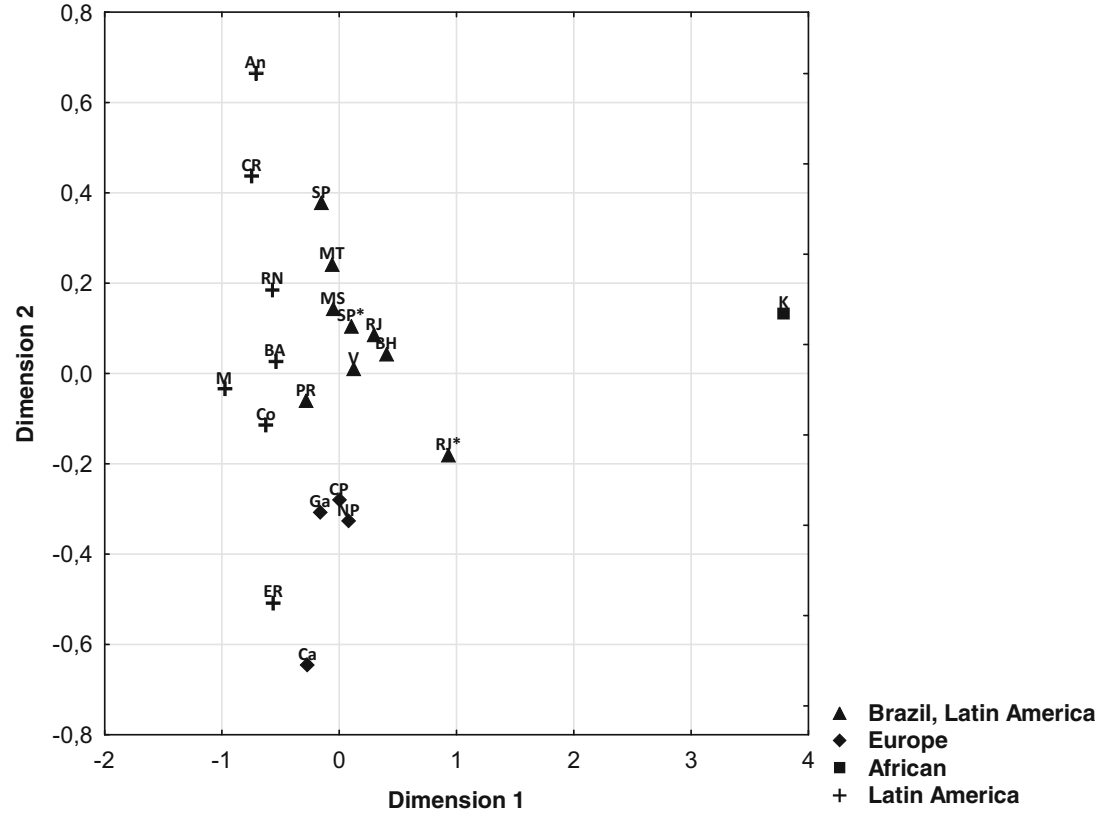

Argentina, Costa Rica and Antioquia have a tri-hybrid population and, for autosomal markers, they show marked European ancestry, followed by Native American ancestry, and a smaller percentage of African ancestry. The African ancestry is very small in Argentina $(65 \% \mathrm{E}, 4 \%$ A, 31\% NA [27]) and in Costa Rica (58\% E, 4\% A, 38\% NA [28]), compared with the percentages in Antioquia $(44.3 \% \mathrm{E}, 21.1 \% \mathrm{~A}$, $34.6 \%$ NA [29]). For markers of X chromosome, the population of Antioquia carries genetic heritage of $37.5 \%$ E, $29 \%$ A and $33.5 \%$ NA, showing greater European contribution, which is very close to the Native American data [30]. In Brazil, as mentioned above, $\mathrm{X}$ ancestry data for the Northeast and Southeast also show greater European contribution, but this value is very close to that of the African population [26]. Statistics show that the number of permanent immigrants in Brazil until 2012 includes Bolivians (50,240 immigrants) and Argentinians (42,202 immigrants) as the main representatives from Latin America, with fewer Colombians (5915 immigrants) and Costa Ricans (only 411 immigrants) [31]. The significant number of immigrants from Argentina into Brazil is one of the factors that may explain the greater genetic similarity of the population of Mato Grosso with Argentinians, in relation to Costa Rica and Antioquia.

Genetic data for the X-STR decaplex system in the population of Mato Grosso confirm its history of colonization. This region was initially occupied by indigenous people. In the fifteenth century, the Treaty of Tordesillas, signed between Spain and Portugal [32], divided the newly discovered lands outside Europe and this territory came under the Spanish rule. However, the Spanish did not settle in this area immediately, as they were attracted by the riches found in the mines in Peru. In the late seventeenth century, explorers (called "Bandeirantes") hailed from Sao Paulo and led expeditions to the west of the country, reaching Minas Gerais, Goiás and Mato Grosso. They extended the territorial control over the Brazilian Midwest and discovered large gold deposits. At that point, Mato Grosso started to receive a large number of Spanish and Portuguese settlers [32-34], as well as settlers from other populated areas of the Portuguese colony, such as São Paulo de Piratininga, São Vincente and the Northeast coast (https://pt.wikipedia.org/wiki/Mineração_ no_Brasil).

In order to meet the increasing demand for mine workers, African slaves were brought to Mato Grosso, especially from Guinea, Angola, Mozambique and the Democratic Republic of Congo [35]. After the mining boom, the State directed the focus to the agricultural sector. As of 1960, substantial investments from the States of Rio Grande do Sul and Paraná for the cultivation of wheat and soybean brought progress to the region, which began to stand out in the Brazilian agricultural sector [36]. In the 1970s and 1980s, an intense migration flow was observed in this promising region, driven by incentive programs for agricultural modernization and interaction of Mato Grosso to other markets [36]. Therefore, the Midwest was the last region to be colonized by individuals from all other Brazilian regions, mainly the Northeast and Southeast [37].

In conclusion, the X-STR decaplex system proved to be extremely useful for biological relationships tests and forensic cases involving the population of the State of Mato Grosso and the data related to population genetic structure does not show the need for a specific forensic database for this State in relation to the Brazilian populations compared in this study, except for the population of Rio de Janeiro. 
The Laboratory of Paternity Investigation of UNESP annually participates in proficiency testing of the Spanish and Portuguese Speaking Working Group of the International Society for Forensic Genetics (GHEP-ISFG).

Acknowledgements The authors would like to thank the Blood Centre of the State of Mato Grosso (MT-Hemocentro) for supporting blood sample collection. This study was granted by Fundação de Apoio à Pesquisa e Extensão de São José do Rio Preto (FAPERP, Protocol no. 027/2014). D.R.S. Souza was the recipient of a fellowship (BAP) from the Medical School of São José do Rio Preto-SP.

Compliance with ethical standards This study was approved by the Research Ethics Committee of the Medical School of São José do Rio Preto-FAMERP (CAAE 39088514.8.0000.5415). All participants were informed of the study and signed an informed consent document.

Conflict of interest The authors declare that they have no conflict of interest.

\section{References}

1. Szibor R (2007) X-chromosomal markers: past, present and future. Forensic Sci Int Gen 1:93-99

2. Toni C, Domenici R, Presciuttini S (2007) Genotype probabilities of pairs of individuals for X-chromosome markers. Transfusion 47: $1276-1280$

3. Pinto N, Gusmão L, Amorim A (2011) X-chromosome markers in kinship testing: a generalisation of the IBD approach identifying situations where their contribution is crucial. Forensic Sci Int Genet 5:27-32

4. Szibor R, Hering S, Edelmann J (2006) A new web site compiling forensic chromosome $\mathrm{X}$ research is now online. Int J Legal Med 120:252-254

5. Nothnagel M, Szibor R, Vollrath O, Augustin C, Edelmann J, Geppert M, Alves C, Gusmão L, Vennemann M, Hou Y, Immel UD, Inturri S, Luo H, Lutz-Bonengel S, Robino C, Roewer L, Rolf B, Sanft J, Shin KJ, Sim JE, Wiegand P, Winkler C, Krawczak M, Hering S (2012) Collaborative genetic mapping of 12 forensic short tandem repeat (STR) loci on the human X chromosome. Forensic Sci Int Genet 6:778-784

6. Martins JA, Kawamura B, Cardoso AE, Cicarelli RMB (2014) Brazilian genetic database of chromosome X. Mol Biol Rep 41: 4077-4080

7. Amorim CE, Wang S, Marrero AR, Salzano FM, Ruiz-Linares BMC (2011) X-chromosomal genetic diversity and linkage disequilibrium patterns in Amerindians and non-Amerindian populations. Am J Hum Biol 23:299-304

8. Gusmão L, Sánchez-Diz P, Alves C, Gomes I, Zarrabeitia MT, Abovich M, Atmetlla I, Bobillo C, Bravo L, Builes J, Cainé L, Calvo R, Carvalho E, Carvalho M, Cicarelli R, Catelli L, Corach D, Espinoza M, García O, Malaghini M, Martins J, Pinheiro F, João Porto M, Raimondi E, Riancho JA, Rodríguez A, Rodríguez A, Rodríguez Cardozo B, Schneider V, Silva S, Tavares C, Toscanini U, Vullo C, Whittle M, Yurrebaso I, Carracedo A, Amorim A (2009) A GEP-ISFG collaborative study on the optimization of an X-STR decaplex: data on 15 Iberian and Latin American populations. Int J Legal Med 123:227-234

9. Ribeiro-Rodrigues EM, Leite FP, Hutz MH, Palha TJ, Ribeiro dos Santos AK, dos Santos SE (2008) A multiplex PCR for 11 X chromosome STR markers and population data from a Brazilian Amazon Region. Forensic Sci Int Genet 2:154-158
10. Ribeiro-Rodrigues EM, Palha TJ, Santos AK, Dos Santos SE (2010) Genetic data of twelve X-STRs in a Japanese immigrant population resident in Brazil. Forensic Sci Int Genet 4:e57-e58

11. Healthcare GE (2010) Reliable extraction of DNA from whatman FTA cards. Application Note 28:9822

12. Martins JA, Costa JC, Paneto GG, Figueiredo RF, Gusmão L, Sánchez-Diz P, Carracedo A, Cicarelli RMB (2010) Genetic profile characterization of $10 \mathrm{X}$-STRs in four populations of the southeastern region of Brazil. Int J Legal Med 124:427-432

13. Excoffier L, Laval G, Schneider S (2005) Arlequinver. 3.0: an in tegrated software package for population genetics data analysis. Evol Bioinformatics Online 1:47-50

14. Gomes I, Pereira V, Gomes V, Prata MJ, Pinto N, Carracedo A, Amorim A, Gusmão L (2009) The Karimojong from Uganda: genetic characterization using an X-STR decaplex system. Forensic Sci Int Genet 3:e127-e128

15. Cainé LM, Zarrabeitia MT, Riancho JA, Fátima Pinheiro M (2010) Genetic data of a Brazilian population sample (Santa Catarina) usingan X-STR decaplex. J Forensic Legal Med 17:272-274

16. Illescas MJ, Pérez A, Aznar JM, Valverde L, Cardoso S, Algorta J, de Pancorbo MM (2012) Population genetic data for 10 X-STR loci in autochthonous Basques from Navarre (Spain). Forensic Sci Int Genet 6:e146-e148

17. Laouina A, Aznar JM, Chbel F, de Pancorbo MM (2013) Genetic data of X-chromosomal STRs in a Moroccan population sample (Casablanca) using an X-STR decaplex. ForensicSci Int Genet 7: e90-e92

18. Szibor R, Hering S, Kuhlisch E, Plate I, Demberger S, Krawczak M, Edelmann J (2005) Haplotyping of STR cluster DXS6801DXS6809-DXS6789 on Xq21 provides a powerful tool for kinship testing. Int J Legal Med 119:363-369

19. Zarrabeitia MT, Pinheiro F, de Pancorbo MM, Cainé L, Cardoso S, Gusmão L, Riancho JA (2009) Analysis of 10 X-linked tetranucleotide markers in mixed and isolated populations. Forensic Sci Int Genet 3:63-66

20. Robino C, Giolitti A, Gino S, Torre C (2006) Development of two multiplex PCR systems for the analysis of $12 \mathrm{X}$-chromosomal STR loci in a northwestern Italian population sample. Int J Legal Med 120:315-318

21. Gomes I, Alves C, Maxzud K, Pereira R, Prata MJ, Sánchez-Diz P, Carracedo A, Amorim A, Gusmão L (2007) Analysis of 10 X-STRs in three African populations. Forensic Sci Int Genet 1:208-211

22. Nakamura Y, Minaguchi K (2010) Sixteen X-chromosomal STRs in two octaplex PCRs in Japanese population and development of 15-locus multiplex PCR system. Int J Legal Med 124:405-414

23. Ribeiro Rodrigues EM, Palha TD, Bittencourt EA, Ribeiro-DosSantos A, Santos S (2011) Extensive survey of 12 X-STRs reveals genetic heterogeneity among Brazilian populations. Int J Legal Med 125:445-452

24. Moura RR, Coelho AV, Balbino VQ, Crovella S, Brandão LA (2015) Meta-analysis of Brazilian genetic admixture and comparison with other Latin America countries. Am J Hum Biol 27:674680

25. Manta FSN, Pereira R, Vianna R, Araújo ARB, Gitaí DLG, Silva DA, Wolfgramm EV, Pontes IM, Aguiar JI, Moraes MO, Carvalho EF, Gusmão L (2013) Revisiting the genetic ancestry of Brazilians using autosomal AIM-Indels. PLoSOne 8:e75145

26. Resque RL, Freitas NSC, Rodrigue EMR, Guerreiro JF, Santos NPC, Santos AR, Zago MA, Santos S (2010) Estimates of interethnic admixture in the Brazilian population using a panelof $24 \mathrm{X}$ linked insertion/deletion markers. Am J Hum Biol 22:849-852

27. Avena S, Via M, Ziv E et al (2012) Heterogeneity in genetic admixture across different regions of Argentina. PLoSOne 7:e34695

28. Ruiz-Narváez EA, Bare L, Arellano A, Catanese J, Campos H (2010) West African and Amerindian ancestry and risk of 
myocardial infarction and metabolic syndrome in the Central Valley population of Costa Rica. Hum Genet 127:629-638

29. Ibarra A, Freire-Aradas A, Martínez M, Fondevila M, Burgos G, Camacho M, Ostos H, Suarez Z, Carracedo A, Santos S, Gusmão L (2014) Comparison of the genetic background of different Colombian populations using the SNPforID 52plex identification panel. Int J Legal Med 128:19-25

30. Ibarra A, Restrepo T, Rojas W, Castillo A, Amorim A, Martínez B, Burgos G, Ostos H, Álvarez K, Camacho M, Suarez Z, Pereira R, Gusmão L (2014) Evaluating the X chromosome-specific diversity of Colombian populations using insertion/deletion polymorphisms. PLoSOne 9:e87202

31. Lima R (2016) Exclusivo: os números exatos e atualizados de estrangeiros no brasil 2013. IOP Publishing Physics Web. http:// oestrangeiro.org/category/analises/page/6/. Accessed 15 Jan 2016
32. Siqueira EM (2009) História de Mato Grosso. Entrelinhas, Cuiabá

33. Silva VW (2011) Controle e domínio territorial no sul do estado de Mato Grosso: uma análise da atuação da Cia Matte Larangeira no período de 1883 a 1937. Agrária 15:102-125

34. Ferreira AC (2009) Conquista colonial, resistência indígena e formação do Estado-Nacional: os índios Guaicuru e Guana no Mato Grosso dos séculos XVIII-XIX. Rev Antropol 52:97-136

35. Rout LB (1976) The African experience in Spanish America: 1502 to the present day. Cambridge University Press, New York

36. Cunha JMP (2006) Dinâmica migratória e o processo de ocupação do Centro-Oeste brasileiro: o caso de Mato Grosso. R Bras Est Pop 23:87-107

37. Palacin L, Moraes MAS (1994) História de Goiás. UCG Goiânia/ Goiás, Brasil 